\title{
Medicina Centrada no Paciente e Capacitação do Consulente em Medicina Geral e Familiar
}

\author{
Patient-Centered Medicine and Enablement in the General Practice / \\ Family Medicine Setting
}

Ana Filipa Reis*, Luiz Miguel Santiago ${ }^{* *}$, Philippe Botas ${ }^{* * *}$

Pontos a reter:

O conceito da Medicina Centrada no Paciente (MCP) data da década de 1980 e nos nossos dias começa a ocupar um papel central nos cuidados médicos. A MCP apresenta-se como uma abordagem que abrange a experiência total de doença do paciente, enfatizando a importância de tomar as crenças e características do mesmo em consideração na tomada de decisões clínicas.

A sua avaliação deve ser feita pelo lado do consulente pelo que se fez trabalho de desenvolvimento de questionário específico e se verificou a sua fiabilidade confrontando os resultados com a Capacitação.

O Questionário MCP-PT para a população portuguesa permite aferir a opinião do consulente sobre a aplicação da MCP durante a consulta com o Médico de Família e verificámos uma correlação positiva entre a MCP e a Capacitação, mesmo que $42,5 \%$ da amostra não tivesse em plenitude percebido os seis componentes da MCP.

Deste modo, compreendemos que um método clínico centrado no paciente, que privilegia a comunicação, a parceria e a promoção de saúde, tem repercussões positivas no paciente, que se sente mais habilitado e capaz de lidar com a sua vida e as suas doenças.

\section{Resumo}

Objetivos: São objetivos deste estudo a validação do Questionário da Medicina Centrada no Paciente em Portugal (MCP-PT), e a verificação da existência de MCP na opinião do consulente, relacionando-a com a Capacitação, segundo instrumento próprio (PEI/ICC).

Tipo de Estudo: Observacional, multicêntrico, não aleatorizado.

Local: Três Unidades de Saúde Familiar do ACeS Baixo Mondego.

\begin{abstract}
Objectives: To validate the questionnaire of Patient-Centered Medicine in Portugal (PCM-PT), in order to get the patients' opinion about the existence of the PCM, and to co-relate it to the Enablement, according to the $\mathrm{PEI} / \mathrm{ICC}$.
\end{abstract}

Design: observational, multicentric, non-randomised.

Setting: Three Family Health Units (FHU), ACeS Baixo Mondego,

\footnotetext{
*Aluna de Mestrado Integrado da Faculdade de Medicina da Universidade e Coimbra.

${ }^{* *}$ MD, PHD, USF Topázio, ACES Baixo Mondego, Faculdade de Ciência da Saúde da Universidade da Beira Interior.

${ }^{* * *} \mathrm{MD}$, Interno de Especialidade de Medicina Geral e Familiar, USF Topázio, ACES Baixo Mondego.
} 
População: Pacientes das USF Topázio, Rainha Santa e Briosa.

Métodos: Construção de MCP-PT segundo os seis componentes da Medicina Centrada no Paciente (MCP) propostos por Moira Stewart e verificação da sua fiabilidade populacional. Aplicação do MCP-PT e do PEI/ICC em duzentos utentes das três USF. Análise das respostas segundo o género, grupo etário, tipo de família, grau de formação, ter doença crónica e tomar medicamentos regularmente. Verificação pela correlação de pearson, se as pontuações obtidas em ambas as escalas fluem em paralelo sendo a de capacitação tanto melhor quanto mais pequena e a de medicina centrada na pessoa tanto melhor quanto mais elevada na relação entre os questionários.

Resultados: O MCP-PT obteve valores de alfa de Cronbach superiores a 0,8, com elevada fiabilidade. A amostra inquirida é maioritariamente feminina, entre 36 e 64 anos, vive acompanhada, tem a $4^{\mathrm{a}}$ classe e toma medicamentos regularmente, referindo 50\% ter doença crónica. No MCP-PT verificamos que $57,5 \%$ dos inquiridos sentem ter sido a consulta em que estiveram sido centrada em si em função da pontuação utilizada e, no PEI/ICC, a resposta "Melhor" foi tendencialmente mais escolhida (58,0\%). O MCP-PT, sendo um indicador composto por vários objetivos, foi estudado em valor absoluto e em distribuição relativa a valores percentílicos. O PEI/ICC tem também valor de indicador que estudámos igualmente. Verificámos correlação entre o MCP-PT e o PEI/ICC, que variam em sentido oposto de valor, $\rho=-0,181, p=0,010$

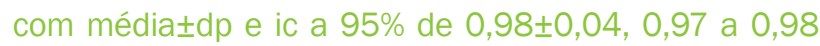

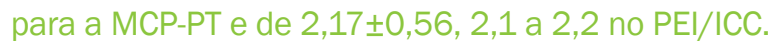

Discussão e Conclusões: A verificação de correlação positiva entre a MCP e a Capacitação permite pensar em melhores resultados terapêuticos da consulta médica se a MCP é realizada. Salientamos a necessidade de se realizarem mais estudos nesta área.

Palavras-chave: Medicina Geral e Familiar, Medicina Centrada no Paciente, Capacitação, Consulta.

\section{Introdução}

O conceito da Medicina Centrada no Paciente (MCP) data da década de 1980 e nos nossos dias começa a ocupar um papel central na assistência médica. ${ }^{1}$ É importante não encarar este método como um processo rigidamente definido, com estágios sequenciais, procedimentos padronizados e estilos de entrevista. ${ }^{2}$ A MCP apresenta-se como uma abordagem que abrange a
Population: Patients from three FHU.

Methods: We built, validated and verified the fiability of the PCM-PT based on the six components of the PCM Moira Stewart proposed. Then the MCP-PT and the PEI was applied to two hundred attendees of the three FHU. We analyzed the answers regarding to gender, age group, family type, academic qualifications, autoperception of sufferance of chronic disease and being regularly on medicines. Correlation between these two questionnaires was studied.

Results: The study sample was mostly composed by 36 to 64 year-old-women, not living alone, with a four-year school degree and taking medications regularly. Half of them suffered from a chronic disease. Most of the answers for the PCM-PT, were "Yes". In the ICC, the option "Better" was the most frequent. Being an indicator with several sub-objectives, the MCP-PT was studied in absolute value and percentile distribution. We also studied the indicator value of the PEI. A positive correlation between the questionnaires was found, with a p-value = 0,010 , their values so being concordant.

Discussion: In this study, we validated the PCM-PT for the portuguese population, based on the patients' opinion on what concerns the implementation of PCM. There is a positive correlation between the PCM and the Enablement that can mean better consultation outcomes. More studies are necessary on this theme.

Keywords: General Practice, Patient-Centered Medicine, Enablement, Consultation.

experiência total de doença do paciente, enfatizando a importância de tomar as crenças e características do mesmo em consideração na tomada de decisões clínicas. ${ }^{3}$ O médico é chamado a identificar as prioridades e preocupações dos consulentes e a envolvê-los na tomada de decisões sobre os seus cuidados. ${ }^{4}$ 
Segundo Moira Stewart in Medicina Centrada na Pessoa ${ }^{1}$, o Método Clínico Centrado na Pessoa divide-se em seis componentes fundamentais:

- Explorando a doença e a experiência de doença (sentimentos, ideias, funcionamento e expectativas);

- Entendendo a pessoa como um todo (conhecer o indivíduo e a sua família);

- Elaborando um plano de cuidados em conjunto (partilha de responsabilidades e aceitação dos objetivos comuns);

- Incorporando Prevenção e Promoção da Saúde (colocar metas, ensinar o que fazer, perceber o que tem que ser feito);

- Intensificando o Relacionamento entre Pessoa e Médico (perceção de que o médico pode continuar a ter tempo, compaixão e poder de partilha, evitando a transferência de responsabilidades);

- Sendo Realista (sobre o tempo da consulta, quanto à intervenção atempada, delegação de competências, comunicação com outros profissionais e trabalho em equipa).

Sabe-se que os pacientes procuram uma abordagem positiva e centrada neles e, se não a encontram, ficam menos satisfeitos, menos capacitados e podem sofrer maior carga de sintomas. . $^{1,5}$

Howie e associados propuseram o conceito de Capacitação que representa o grau em que um paciente se sente fortalecido após uma consulta médica, em termos de ser capaz de lidar, compreender e gerir a sua doença. ${ }^{6}$ Estudos anteriores mostraram que a capacitação do paciente pode ser aumentada pela empatia do médico, a familiaridade do paciente com este, uma avaliação positiva do consulente sobre a comunicação do médico, bem como a maior duração da consulta e o treino apropriado do profissional de saúde. ${ }^{7}$ Todos estes pontos poderiam ser garantidos se existisse, em todas as consultas, a preocupação de aplicar uma MCP. Cada encontro médico pode, de certa forma, influenciar a procura de ajuda pelo paciente no futuro e, reconhecer isto, deve levar a um melhor tratamento, ou abordagem, do doente em cada consulta. ${ }^{1,2,5,8}$ Os atributos do médico e as características da relação são os fatores que tornam terapêutico o relacionamento entre a pessoa e o profissional de saúde. ${ }^{1}$

Existia já um utensílio que permitia medir a Capacitação pela consulta, validado para Portugal, designado por Instrumento de Capacitação do Consulente (PEI/ICC). ${ }^{9}$ No entanto, subsistia a lacuna de um Questionário sobre a Medicina Centrada no Paciente validado para a população portuguesa (MCP-PT). Tornava-se pertinente o desenvolvi- mento desta ferramenta de avaliação do método clínico na consulta, tendo por base a opinião do paciente. A filosofia da OMS evidencia a importância de envolver a comunidade no desenvolvimento, implementação e avaliação dos serviços. ${ }^{10}$ Além disso, os médicos não se encontram muito habilitados para prever a satisfação dos pacientes. ${ }^{11}$

Não existindo em Portugal estudos com o Questionário MCP-PT e sendo escasso o trabalho na área da Capacitação com o PEI/ICC, torna-se inquestionável a pertinência deste trabalho.

Os objetivos deste estudo são a verificação da fiabilidade do Questionário MCP-PT em Portugal, a avaliação da existência de MCP conforme a opinião do consulente, e relacioná-lo com a Capacitação segundo o PEI/ICC.

\section{Materiais e Métodos}

Após parecer favorável da Comissão de Ética para a Saúde da ARS do Centro, I.P., a 23 de janeiro de 2014, iniciámos a validação do questionário específico para medição da realização da consulta segundo o modelo centrado no paciente. Este questionário foi construído segundo o princípio da MCP em seis componentes ${ }^{1}$ e de acordo com os objetivos estabelecidos para o estudo. Inclui doze perguntas e três opções de resposta (Sim, Não ou Em parte). [Anexo 1]

Segundo Moira Stewart ${ }^{1}$ o primeiro domínio da MCP é "Explorando a Doença e a Experiência da Doença". Para este princípio criámos duas questões: "Pôde falar sobre o que sentia e sobre os motivos que o levaram à consulta?" e "Pôde falar sobre os seus receios e as suas esperanças quanto aos seus problemas?”. O segundo domínio é “Entendendo a Pessoa Como um Todo", para o qual existe a pergunta "Sentiu que o médico se interessa por si, pela sua família e pelas suas condições de vida?”. O terceiro domínio, "Elaborando um Plano de Cuidados em Conjunto", gerou as perguntas "Sentiu que o processo de tratamento será realizado em conjunto e colaboração entre si e o seu médico?", "Entendeu os objetivos, métodos e possibilidades em relação ao "tratamento" escolhido?" e "Percebeu a importância de cumprir as indicações para um "tratamento" correto e que dê resultados?". Para o quarto domínio, "Incorporando Prevenção e Promoção da Saúde", surgiram as questões "Percebeu o que deve ser feito para evitar "piorar"?" e "Aceitou fazer o que lhe foi proposto para "melhorar"?". Ao quinto domínio, "Intensificando o Relacionamento Entre Pessoa e Médico”, coube a questão "Sentiu que o médico se mostrou interessado em ajudar a resolver o seu problema?" e, por último, ao sexto domínio, "Sendo Realista", associaram-se 
as perguntas "Compreendeu que o sucesso do tratamento depende de si como doente e de outros profissionais que trabalham com o seu médico?", "A consulta com o seu médico durou o tempo necessário?" e "Esta consulta com o seu médico aconteceu no momento certo?".

Cada um dos seis componentes funciona como um Objetivo a cumprir. Criámos um indicador composto (MCP-PT Total) que é o resultado-média dos seis indicadores parcelares, correspondentes aos Objetivos, e que se calcula pelo somatório das respostas dadas a cada um destes indicadores parcelares e posterior divisão por seis.

O processo de validação iniciou-se com a opinião de um painel de peritos composto por duas sociólogas, uma assistente social, dois psicólogos, uma enfermeira, dois médicos e três indivíduos não ligados à saúde pelo método das rondas sucessivas até à estabilização, que determinou que as perguntas respondiam aos propósitos traçados. Algumas questões foram modificadas na sua forma inicial.

Posteriormente, aplicámos o questionário a um conjunto populacional de trinta consulentes em consulta de Medicina Geral e Familiar, incluindo alguns diabéticos, alguns hipertensos, em consulta de saúde da mulher e em consulta de saúde infantil (sendo o questionário realizado ao progenitor) primeiro por escrito e, alguns minutos depois, oralmente, por intermédio da investigadora, numa das USF. Foram medidos todos os tempos de resposta e aplicado o teste Alfa de Cronbach para verificar diferenças em cada aplicação do questionário. Foi estudada também a diferença de respostas entre as variáveis consideradas.

Após a validação realizámos um estudo observacional e analítico, aplicando o questionário a uma amostra populacional calculada para representar, com um intervalo de confiança de $95 \%$ e uma margem de erro de $6 \%$, a população atendida numa USF durante uma semana de trabalho, o que corresponde a um universo esperado de 625 consultas semanais, dado não haver quaisquer outros resultados nem tão pouco se saber como se distribuiriam os resultados populacionalmente. Deste modo, a amostra deveria compreender pelo menos 189 consulentes. Realizámos 200 questionários, de março a julho de 2014, distribuídos por três Unidades de Saúde Familiar (USF) da Zona Centro de Portugal: USF 1 (66 inquéritos), USF 2 (67 inquéritos) e USF 3 (67 inquéritos). A amostra colhida e estudada é de conveniência e corresponde a consulentes que foram convidados a colaborar quando saíam das consultas, consecutivamente.
Ao inquérito supracitado foi adicionado o Questionário PEI/ICC que permite medir a Capacitação e que já foi validado para a população portuguesa. ${ }^{9}$ [Anexo 1]

Este Questionário é avaliado por um indicador que designámos por PEI/ICC Total que representa a média das respostas dadas às seis questões colocadas.

Os consulentes foram abordados à saída da consulta de Medicina Geral e Familiar.

Os resultados foram estudados segundo o sexo (Feminino e Masculino), Grupo etário (menor ou igual a 35 anos, 36 a 64 anos, maior ou igual a 65 anos), Escolaridade (Não sabe ler e escrever; Sabe ler e escrever; Com $9^{\circ}$ ano ( $4^{\mathrm{a}}$ classe); $12^{\circ}$ ano ( $7^{\circ}$ ano); Técnica; Superior), Grau de Formação [Baixo se $\leq 9^{\circ}$ ano ( $4^{a}$ classe) e Médio/Alto se $\geq 12^{\circ}$ ano ( $7^{\circ}$ ano)], Viver só ou acompanhado, ter ou não uma doença crónica e tomar ou não medicação regularmente. A Investigadora, devidamente identificada, aplicou os questionários oralmente num local não visível pelos médicos e trabalhou em dias estabelecidos pela própria, sem que a USF tivesse conhecimento das datas exatas da sua presença.

Todos os questionários tinham uma declaração de consentimento informado e foram sempre respeitados o anonimato e a confidencialidade.

Utilizámos o software "SPSS software for Windows version 19.0" (SPSS Inc, Chicago, IL) para a estatística e a análise inferencial dos dados obtidos, após verificação da sua normalidade. Quando analisadas variáveis nominais, utilizámos o teste $X^{2}$; em variáveis numéricas contínuas com distribuição normal em amostras independentes empregámos o teste t de Student; se a distribuição não era normal, utilizámos os testes não paramétricos Mann-Whitney U e Kruskal-Wallis. Definiu-se como estatisticamente significativo o valor de $p<0,05$.

\section{Resultados}

A população de trinta utentes inquirida durante a fase de validação do questionário MCP-PT, na USF Topázio, é composta por 13 indivíduos do género masculino (43,3\%) e 17 do género feminino (56,7\%). A média de idades é de $56,9 \pm 22,1$ anos, sendo que 16,7\% têm 35 anos ou menos, 23,3\% têm entre 36 e 64 anos e $60 \%$ têm 65 anos ou mais. Apenas um utente vive só (3,3\%), sendo que os restantes vivem acompanhados $(96,7 \%)$. Em relação às habilitações académicas da amostra, 4 inquiridos não sabem ler ou escrever (13,3\%), 4 sabem ler e escrever (13,3\%), 11 concluíram o $9^{\circ}$ ano (4ª classe) $(36,7 \%), 6$ 
terminaram o $12^{\circ}$ ano ( $7^{\circ}$ ano) $(20,0 \%), 1$ tem um curso Técnico (3,3\%) e 4 um curso Superior (13,3\%). Metade dos respondentes tem doenças crónicas, sendo que a outra metade não tem. 20 (66,7\%) consulentes afirmam tomar medicação regularmente e 10 (33,3\%) negam.

0 tempo médio de resposta foi de $3,5 \pm 1,2$ minutos (intervalo de confiança a 95\% de 2,8 a 3,7 minutos), com um mínimo de 2 e um máximos de 6 minutos.

Não foram verificadas diferenças significativas nas respostas em função das variáveis estudadas.
A Tabela I mostra o teste de Alfa de Cronbach para cada Afirmação do Questionário MCP-PT. Verificámos que, para todas as questões, o seu valor foi superior a 0,8.

Na análise das respostas em função das variáveis, sexo, tipo de família, grau de formação académica, considerar sofrer de doença crónica, tomar regularmente medicamentos e grupo etário, não foram encontradas quaisquer diferenças nas doze perguntas do MCP-PT pelos testes $U$ de Mann-Whitney e Kruskal-Wallis.

Tabela I: Teste de Alfa de Cronbach para as questões do MCP-PT, numa amostra de trinta consulentes, durante a fase de validação, na USF Topázio.

\begin{tabular}{|c|c|}
\hline Afirmação & $\begin{array}{l}\text { Alfa de } \\
\text { Cronbach }\end{array}$ \\
\hline Pôde falar sobre o que sentia e sobre os motivos que o levaram à consulta? & 1 \\
\hline Pôde falar sobre os seus receios e as suas esperanças quanto aos seus problemas? & 0,852 \\
\hline Sentiu que o médico se interessa por si, pela sua família e pelas suas condições de vida? & 1 \\
\hline $\begin{array}{l}\text { Sentiu que o processo de tratamento será realizado em conjunto e colaboração entre si e o seu } \\
\text { médico? }\end{array}$ & 1 \\
\hline Entendeu os objetivos, métodos e possibilidades em relação ao "tratamento" escolhido? & 1 \\
\hline $\begin{array}{l}\text { Percebeu a importância de cumprir as indicações para um "tratamento" correto e que dê } \\
\text { resultados? }\end{array}$ & 1 \\
\hline Percebeu o que deve ser feito para evitar "piorar"? & 1 \\
\hline Aceitou fazer o que Ihe foi proposto para "melhorar"? & 1 \\
\hline Sentiu que o médico se mostrou interessado em ajudar a resolver o seu problema? & 1 \\
\hline $\begin{array}{l}\text { Compreendeu que o sucesso do tratamento depende de si como doente e de outros } \\
\text { profissionais que trabalham com o seu médico? }\end{array}$ & 1 \\
\hline A consulta com o seu médico durou o tempo necessário? & 1 \\
\hline Esta consulta com o seu médico aconteceu no momento certo? & 1 \\
\hline Todos os items & 0,899 \\
\hline
\end{tabular}

De seguida, aplicámos os questionários MCP-PT e PEI/ ICC numa população de duzentos consulentes nas USF Topázio, Rainha Santa e Briosa. Nesta amostra, a média de idades é de 51,4 anos, sendo que $46 \%$ dos consulentes têm idades compreendidas entre os 36 e os 64 anos, 32\% têm 65 anos ou mais e 22\% têm 34 anos ou menos. A maioria dos inquiridos, $85 \%$, vive acompanhada e $15 \%$ vivem sozinhos. Do total de respondentes ao questionário, 63\% são do género feminino e 37\% do género masculino. Em relação à formação académica, $7 \%$ não sabe ler nem escrever, 5,5\% apenas sabe ler e escrever, $36,5 \%$ concluiu o $9^{\circ}$ ano (4 $4^{\text {a }}$ classe), $18,5 \%$ terminou o $12^{\circ}$ ano ( $7^{\circ}$ ano), 5,5\% tem um curso técnico e $27 \%$ um curso superior. Deste modo, $49 \%$ dos inquiridos apresentam um grau de Formação básico e 51\% médio/alto. Dos 200 pacientes, 101 (50,5\%) sofrem de doença crónica e os restantes $(49,5 \%)$ não. Por fim, 133 (66,5\%) afirmam tomar medicação regular e 67 (33,5\%) negam.

A Tabela II mostra a distribuição das respostas ao MCP-PT pelos 200 consulentes inquiridos. 
Tabela II: Distribuição das respostas ao Questionário MCP-PT de duzentos consulentes das 3 USF.

\begin{tabular}{|c|c|c|c|}
\hline Pergunta & $\begin{array}{l}\text { Não } \\
\text { n (\%) }\end{array}$ & $\begin{array}{l}\text { Em parte } \\
\text { n (\%) }\end{array}$ & $\operatorname{Sim}$ \\
\hline $\begin{array}{l}\text { Pôde falar sobre o que sentia e sobre os motivos que o levaram } \\
\text { à consulta? }\end{array}$ & 0 & $\begin{array}{c}6 \\
(3,0)\end{array}$ & $\begin{array}{c}194 \\
(97,0)\end{array}$ \\
\hline $\begin{array}{l}\text { Pôde falar sobre os seus receios e as suas esperanças quanto } \\
\text { aos seus problemas? }\end{array}$ & $\begin{array}{c}10 \\
(5,0)\end{array}$ & $\begin{array}{c}13 \\
(6,5)\end{array}$ & $\begin{array}{c}177 \\
(88,5)\end{array}$ \\
\hline $\begin{array}{l}\text { Sentiu que o médico se interessa por si, pela sua família e pelas } \\
\text { suas condições de vida? }\end{array}$ & $\begin{array}{c}1 \\
(0,5)\end{array}$ & $\begin{array}{c}11 \\
(5,5)\end{array}$ & $\begin{array}{c}188 \\
(94,0)\end{array}$ \\
\hline $\begin{array}{l}\text { Sentiu que o processo de tratamento será realizado em conjunto } \\
\text { e colaboração entre si e o seu médico? }\end{array}$ & $\begin{array}{c}3 \\
(1,5)\end{array}$ & $\begin{array}{c}2 \\
(1,0)\end{array}$ & $\begin{array}{c}195 \\
(97,5)\end{array}$ \\
\hline $\begin{array}{l}\text { Entendeu os objetivos, métodos e possibilidades em relação ao } \\
\text { "tratamento" escolhido? }\end{array}$ & $\begin{array}{c}3 \\
(1,5)\end{array}$ & $\begin{array}{c}11 \\
(5,5)\end{array}$ & $\begin{array}{c}186 \\
(93,0)\end{array}$ \\
\hline $\begin{array}{l}\text { Percebeu a importância de cumprir as indicações para um } \\
\text { "tratamento" correto e que dê resultados? }\end{array}$ & 0 & $\begin{array}{c}2 \\
(1,0)\end{array}$ & $\begin{array}{c}198 \\
(99,0)\end{array}$ \\
\hline Percebeu o que deve ser feito para evitar "piorar"? & $\begin{array}{c}3 \\
(1,5)\end{array}$ & $\begin{array}{c}8 \\
4,0)\end{array}$ & $\begin{array}{c}189 \\
(94,5)\end{array}$ \\
\hline Aceitou fazer o que Ihe foi proposto para "melhorar"? & 0 & $\begin{array}{c}12 \\
(6,0)\end{array}$ & $\begin{array}{c}188 \\
(94,0)\end{array}$ \\
\hline $\begin{array}{l}\text { Sentiu que o médico se mostrou interessado em ajudar a } \\
\text { resolver o seu problema? }\end{array}$ & 0 & $\begin{array}{c}9 \\
(4,5)\end{array}$ & $\begin{array}{c}101 \\
(95,5)\end{array}$ \\
\hline $\begin{array}{l}\text { Compreendeu que o sucesso do tratamento depende de si como } \\
\text { doente e de outros profissionais que trabalham com o seu médico? }\end{array}$ & 0 & $\begin{array}{c}8 \\
(4,0)\end{array}$ & $\begin{array}{c}192 \\
(96,0)\end{array}$ \\
\hline A consulta com o seu médico durou o tempo necessário? & $\begin{array}{c}3 \\
(1,5)\end{array}$ & $\begin{array}{c}11 \\
(5,5)\end{array}$ & $\begin{array}{c}186 \\
(93,0)\end{array}$ \\
\hline Esta consulta com o seu médico aconteceu no momento certo? & $\begin{array}{c}6 \\
(3,0)\end{array}$ & $\begin{array}{c}24 \\
(12,0)\end{array}$ & $\begin{array}{c}170 \\
(85,0)\end{array}$ \\
\hline
\end{tabular}

Na Tabela III, mostramos a distribuição, por percentis, das respostas obtidas para cada objetivo que se pretende medir no MCP-PT. É de realçar que o valor do Percentil 50 (P50) é igual ao do Percentil 75 (P75).
Considerámos que não foi percebida a MCP quando a distribuição percentílica era inferior ao P50 e que foi percebida quando esta distribuição era superior, como descrito na Tabela IV. 
Tabela III: Distribuição, por percentis, das respostas obtidas para cada objetivo.

\begin{tabular}{|c|c|c|c|}
\hline Objetivo & $\begin{array}{c}\text { Valor } \\
\text { P50 / P25 }\end{array}$ & $\begin{array}{c}n(\%) \text { para } \\
\text { P } \geq 50\end{array}$ & $\begin{array}{c}n(\%) \text { de } \\
\text { P } \leq 25\end{array}$ \\
\hline 1. Explorando a doença e a experiência de doença & $6 / 6$ & $174(87,0)$ & $26(13,0)$ \\
\hline 2. Entendendo a pessoa como um todo & $3 / 3$ & $188(94,0)$ & $12(6,0)$ \\
\hline 3. Elaborando um plano de cuidados em conjunto & $9 / 9$ & $180(90,0)$ & $20(10,0)$ \\
\hline 4. Incorporando prevenção e promoção da saúde & $6 / 6$ & $179(89,5)$ & $21(10,5)$ \\
\hline 5. Intensificando o relacionamento entre pessoa e médico & $3 / 3$ & $191(96,5)$ & $9(4,5)$ \\
\hline 6. Sendo Realista & $9 / 9$ & $159(79,5)$ & $41(20,5)$ \\
\hline
\end{tabular}

O valor do indicador MCP é dado pelo média das pontuações a cada um dos domínios, sendo para este estudo de $0,98 \pm 0,04$ ic a $95 \%$ de 0,97 a 0,98. A distribuição das respostas ao MCP-PT por variável, em função de ter sido sentida ou não a MCP é mostrada na Tabela IV. Existe diferença estatisticamente significativa para o Grau de Formação $(p=0,025)$ e para o Grupo Etário $(p=0,004)$.
Para as restantes variáveis não se encontraram diferenças estatisticamente significativas.

Tabela IV: Resultado global da aplicação do MCP-PT pelas variáveis consideradas em função de ter sido percebida a Medicina Centrada no Paciente, de acordo com a distribuição percentílica.

\begin{tabular}{|c|c|c|c|}
\hline Variável & $\begin{array}{c}\text { Sentido } \\
\text { n (\%) }\end{array}$ & $\begin{array}{l}\text { Não sentido } \\
\text { n (\%) }\end{array}$ & $p$ \\
\hline \multicolumn{4}{|l|}{ Sexo $\left({ }^{*}\right)$} \\
\hline Masculino & $41(55,4)$ & $33(44,6)$ & \multirow{2}{*}{0,377} \\
\hline Feminino & $74(58,7)$ & $52(41,3)$ & \\
\hline \multicolumn{4}{|l|}{ Família $\left(^{*}\right)$} \\
\hline Só & $18(60,0)$ & $12(40,0)$ & \multirow{2}{*}{0,463} \\
\hline Acompanhado & $97(7,1)$ & $73(42,99)$ & \\
\hline \multicolumn{4}{|l|}{ Grau de formação (*) } \\
\hline Baixa & $49(50,0)$ & $49(50,0)$ & \multirow{2}{*}{0,025} \\
\hline Média/Alta & $66(64,7)$ & $36(35,3)$ & \\
\hline \multicolumn{4}{|l|}{ Sofrer de doença crónica $\left(^{*}\right)$} \\
\hline Sim & $54(53,5)$ & $47(46,5)$ & \multirow{2}{*}{0,153} \\
\hline Não & $61(61,6)$ & $38(38,4)$ & \\
\hline \multicolumn{4}{|c|}{ Tomar medicamentos regularmente $\left(^{*}\right)$} \\
\hline Sim & $72(54,1)$ & $61(45,9)$ & \multirow{2}{*}{0,114} \\
\hline Não & $43(64,2)$ & $24(35,8)$ & \\
\hline \multicolumn{4}{|l|}{ Grupo etário $(* *)$} \\
\hline Menor ou igual a 35 anos & $35(79,5)$ & $9(20,5)$ & \multirow{3}{*}{0,004} \\
\hline 36 a 64 anos & $47(51,1)$ & $45(48,9)$ & \\
\hline Maior ou igual a 65 anos & $33(51,6)$ & $31(48,4)$ & \\
\hline
\end{tabular}

Nota: $\left({ }^{*}\right) X^{2} ;(* *)$ Kruskal-Wallis $\left(X^{2}=11,166, d f=2\right)$ 
A Tabela $V$ mostra a distribuição das respostas ao PEI/ ICC pelos duzentos consulentes inquiridos.

No questionário PEI/ICC verificámos que a maioria dos inquiridos respondia "Melhor" em todas as perguntas (48 a 57\%). De seguida, a preferência está na resposta "Igual ou pior" (26,5 a 37\%) e, por fim, na resposta "Muito Melhor" (8,5 a 18\%).
O P50 do MCP-PT Total é 1,0000 e do PEI/ICC Total é 2,1700 .

Tabela V: Distribuição das respostas ao Questionário PEI/ ICC de duzentos consulentes das 3 USF.

\begin{tabular}{lcc|c} 
Pergunta & $\begin{array}{c}\text { Muito melhor } \\
n(\%)\end{array}$ & $\begin{array}{c}\text { Melhor } \\
n(\%)\end{array}$ & $\begin{array}{c}\text { Igual ou pior } \\
n(\%)\end{array}$ \\
\hline Capaz de lidar com a vida & $17(8,5)$ & $109(54,5)$ & $74(37,0)$ \\
\hline Capaz de compreender a sua doença & $29(14,5)$ & $109(54,5)$ & $62(31,0)$ \\
\hline Capaz de lidar com a sua doença & $29(14,5)$ & $110(55,0)$ & $61(30,5)$ \\
\hline Capaz de manter-se saudável & $29(14,5)$ & $114(57,0)$ & $57(28,5)$ \\
\hline Confiante em relação à sua saúde & $36(18,0)$ & $96(48,0)$ & $68(34,0)$ \\
\hline Capaz de se ajudar a si próprio & $35(17,5)$ & $112(56,0)$ & $53(26,5)$
\end{tabular}

Considerámos que não há melhoria da Capacitação quando a distribuição percentílica do indicador calculado (média das pontuações) é superior ao P50 e que há melhoria quando esta distribuição é inferior.

Na Tabela VI é mostrada a distribuição das respostas ao $\mathrm{PEI} / \mathrm{ICC}$ segundo as variáveis consideradas em função de a pontuação global estar acima ou abaixo do percentil 50. Existe diferença estatisticamente significativa na variável género $(p=0,048)$. Para as restantes variáveis não foram encontradas diferenças estatisticamente significativas.

Tabela VI: Distribuição das respostas ao PEI/ICC segundo o Género, Família, Grau de formação, Sofrer de doença crónica, Tomar medicamentos regularmente e Grupo etário em função da situação quanto ao Percentil 50 sendo a situação de inferior a P50 a de capacitação e a de estar acima de P50 de não capacitação.

\begin{tabular}{|c|c|c|c|}
\hline Variável & $\begin{array}{l}\text { Menor que } \\
\text { Percentil } 50\end{array}$ & $\begin{array}{l}\text { Maior que } \\
\text { percentil } 50\end{array}$ & $p$ \\
\hline \multicolumn{4}{|l|}{ Sexo $(*)$} \\
\hline Masculino & $25(33,8)$ & $49(66,2)$ & \multirow{2}{*}{0,048} \\
\hline Feminino & $59(46,8)$ & $67(53,2)$ & \\
\hline \multicolumn{4}{|l|}{ Família $(*)$} \\
\hline Só & $13(43,3)$ & $17(56,7)$ & \multirow{2}{*}{0,513} \\
\hline Acompanhado & $71(41,8)$ & $99(58,2)$ & \\
\hline \multicolumn{4}{|c|}{ Grau de formação $(*)$} \\
\hline Baixa & $43(43,9)$ & $55(56,1)$ & \multirow{2}{*}{0,350} \\
\hline Média/Alta & $41(40,2)$ & $61(59,8)$ & \\
\hline \multicolumn{4}{|c|}{ Sofrer de doença crónica $\left({ }^{*}\right)$} \\
\hline Sim & $39(38,6)$ & $72(61,4)$ & \multirow{2}{*}{0,201} \\
\hline Não & $45(45,5)$ & $54(54,5)$ & \\
\hline
\end{tabular}




\begin{tabular}{|c|c|c|c|}
\hline \multicolumn{4}{|c|}{ Tomar medicamentos regularmente (*) } \\
\hline Sim & $53(39,8)$ & $80(60,2)$ & \\
\hline Não & $31(46,3)$ & $36(53,7)$ & 0,237 \\
\hline \multicolumn{4}{|l|}{ Grupo etário (**) } \\
\hline Menor ou igual a 35 anos & $23(52,3)$ & $21(47,7)$ & \\
\hline 36 a 64 anos & $38(41,3)$ & $54(58,7)$ & 0,237 \\
\hline Maior ou igual a 65 anos & $23(35,9)$ & $41(64,1)$ & \\
\hline
\end{tabular}

Definiu-se que para valores acima do P50 (1,0000) para o MCP-PT Total haveria boa MCP na consulta com o Médico de Família. Para o PEI/ICC Total considera-se que os valores abaixo do P50 $(2,1700)$ teriam respostas compatíveis com uma melhor Capacitação após a consulta.

O MCP-PT Total tem como média 0,98 $\pm 0,04$, mediana 1,00, moda 1,00 e intervalo de confiança de 95\% entre 0,97 e 0,98. O PEl/ICC Total tem como média 2,2 $\pm 0,6$, mediana 2,2, moda 2,0 e intervalo de confiança de 95\% entre 2,1 e 2,2 .

\begin{tabular}{c|c} 
MCP-PT Total & n (\%) \\
\hline Sim & $115(57,5)$ \\
\hline Não & $85(42,5)$ \\
\hline
\end{tabular}

Uma vez que o Questionário MCP-PT e o Questionário $\mathrm{PEI} / \mathrm{ICC}$ variam em sentido contrário, isto é, é tanto meIhor quanto maior valor numérico do MCP-PT e quanto menor o valor numérico do PEI/ICC, o valor de $\mathrm{p}$ terá de ser inferior a 0,05 para que haja uma correlação
Como observamos na Tabela VII, 57,5\% dos inquiridos responde ter tido uma consulta segundo o método clínico da MCP e 58,0\% responde admitir melhor capacitação após a consulta.

Tabela VII: \% Cumulativa do MCP-PT Total e do PEI/ICC Total, consoante sentem ou não MCP na consulta e conforme melhoram ou pioram a Capacitação.

\begin{tabular}{cc} 
PEI/ICC Total & $n(\%)$ \\
\hline Melhor & $116(58,0)$ \\
\hline Pior & $84(42,0)$ \\
\hline
\end{tabular}

estatisticamente significativa. Neste caso, segundo a Tabela VIII, verificámos que o p é de 0,010.

Tabela VIII: Correlação entre o MCP-PT Total e o PEI/ ICC Total.

\begin{tabular}{|c|c|c|c|}
\hline & & MCP-PT Total & PEI/ICC Total \\
\hline \multirow[t]{3}{*}{ Resultado final MCP-PT } & Correlação de Pearson & 1 & $-0,181$ \\
\hline & P de duas caudas & & 0,010 \\
\hline & N & 200 & 200 \\
\hline \multirow[t]{3}{*}{ Resultado final PEI/ICC } & Correlação de Pearson & $-0,181$ & 1 \\
\hline & P de duas caudas & 0,010 & \\
\hline & N & 200 & 200 \\
\hline
\end{tabular}




\section{Discussão}

O encontro clínico entre o paciente e o médico é a principal atividade de todos os sistemas de cuidados de saúde, em especial no ambiente de $\mathrm{MGF}^{7} \mathrm{Na}$ tentativa de melhorar este contato terapêutico, o método clínico centrado na pessoa foi desenvolvido para lidar com a complexidade. ${ }^{1}$ Já tendo sido demonstrado o valor e a utilidade dos contributos dos doentes para a melhoria dos cuidados de saúde, torna-se importante criar ferramentas capazes de avaliar a opinião do consulente relativamente a este tipo de consulta. ${ }^{12}$

Neste sentido, surgiu a necessidade de criar e validar para a população portuguesa um Questionário que aprecia a existência de MCP segundo a opinião do utente.

Baseámo-nos nos seis Componentes da MCP propostos por Moira Stewart in Medicina Centrada no Paciente ${ }^{1}$ uma vez que, na nossa opinião, estes representam bem os objetivos esperados alcançar durante uma consulta, em particular de Medicina Geral e Familiar.

Aplicámos o questionário MCP-PT, depois de verificada a sua consistência interna para verificarmos a sua fiabilidade, e o questionário $\mathrm{PEI} / \mathrm{ICC}$, que recentemente foi traduzido para Portugal e com fiabilidade verificada, numa amostra de duzentos consulentes nas três USF, após consentimento dos coordenadores das referidas USF. ${ }^{(2)}$

Na fase de verificação de consistência interna, os autores depararam-se com a dificuldade que alguns inquiridos tinham de responder apenas em função da consulta que tinha decorrido. A investigadora tentou evitar o viés de observação ao realizar o questionário em datas selecionadas pela própria e não divulgadas à USF e estando num local não visível aos médicos de serviço. Por outro lado, a recolha foi feita em mais do que um dia da semana, para que se abrangesse um leque mais vasto de utentes, evitando dias de férias de algum médico, ou dias de problemas mais específicos.

A aplicação destas duas ferramentas de avaliação das consultas pelo utente tinha a intenção de inferir se a MCP teria co-relação com a Capacitação, desde já se ressalvando que outros trabalhos serão necessários para consolidar os deste trabalho pioneiro.

Sabemos que este termo, proposto pela primeira vez por Howie et al, se refere ao ganho que efetivamente o consulente adquire numa consulta para poder compreender e lidar com a sua doença o melhor possível. ${ }^{13}$ Ao comprovarmos que a MCP corresponde a uma melhoria da
Capacitação, estaremos, mais uma vez, a validar o Questionário MCP-PT, premiando o modelo clínico descrito por Moira Stewart em seis componentes. ${ }^{1}$

A amostra inquirida é compatível com o expectável numa USF, com uma maioria de mulheres, entre os 36 e 64 anos, que vivem acompanhadas, com a $4^{a}$ classe e a tomar medicamentos regularmente, metade das quais com alguma doença crónica.

A distribuição das respostas no MCP-PT, com propensão significativa para a resposta "Sim", pareceu-nos indicativa da tendência para a MCP nas consultas das diversas USF. No que diz respeito ao $\mathrm{PEI} / \mathrm{ICC}$, a resposta intermédia "Melhor" foi tendencialmente mais escolhida, dando-nos a sensação de que de fato há uma melhoria na Capacitação após a consulta, mas não suficiente para que os utentes respondam "Muito Melhor".

De seguida, avaliámos a distribuição das respostas ao MCP-PT por variável testada, em função de se sentir ou não a MCP, de acordo com a distribuição percentílica.

Percebemos que existem diferenças estatisticamente significativas para o Grau de Formação $(p=0,025)$ e para o Grupo Etário $(p=0,004)$ em função de ter sentido ou não a MCP segundo as respostas dadas ao MCP-PT. Os inquiridos com um Grau de Formação Médio/Alto tendem a sentir mais a MCP e os consulentes do Grupo Etário mais baixo, com idades iguais ou inferiores a 35 anos, também seguem essa tendência.

Parece-nos que esta propensão dos mais novos e dos com maior grau de escolaridade sentirem a MCP pode ser explicada pela maior facilidade com que percebem o discurso médico e interagem com figuras detentoras do conhecimento, numa perspetiva de modelo de Medicina Não Paternalística.

No questionário $\mathrm{PEI} / \mathrm{ICC}$, percebemos que existe diferença estatisticamente significativa na variável Género ( $p=0,048)$, em função de não existir ou existir melhoria na Capacitação.

Assim, os indivíduos do género masculino, na sua maioria (66,2\%), não sentem uma melhoria da Capacitação e no género feminino, apesar de se notar a mesma tendência, esta é mais ténue (53,2\%). Esta propensão masculina para uma menor Capacitação poderá ter explicação em alguma dificuldade em fazer perguntas e pedir justificações ao médico durante a consulta ou na mais fácil aceitação do que é dito, não questionando, nem interiorizando. 
Deste modo, ficámos a saber que $57,5 \%$ dos inquiridos tiveram uma consulta onde consideraram que a MCP foi aplicada e 58\% dos respondentes aumentaram a sua Capacitação após a consulta. Ambos os resultados parecem corresponder a uma melhoria na satisfação e habilitação dos doentes após o encontro clínico, no entanto, estes resultados ainda não abrangem uma maioria incontestável da população.

Em futuros estudos será interessante desvendar que parte da amostra mais revela uma MCP positiva e um maior aumento da Capacitação. Poderá também ser importante distinguir quais os objetivos da MCP que estão a ser mais negligenciados pelos médicos durante a consulta. Por não corresponder ao propósito deste estudo não nos alargaremos mais em considerações sobre estes tópicos.

Quisemos, então, verificar se existia uma correlação positiva entre a MCP e a Capacitação. Uma vez que o Questionário MCP-PT e o Questionário PEI/ICC variam em sentido contrário, isto é, é melhor quanto maior o resultado do MCP-PT e quanto menor o resultado do PEI/ ICC, o valor de $\mathrm{p}$ teria de ser inferior a 0,05 para que existisse uma correlação estatisticamente significativa. Como o resultado que encontrámos para $p$ foi 0,010 podemos inferir que há correlação entre o MCP-PT e o $\mathrm{PEI} / \mathrm{ICC}$, revelando que uma MCP aumenta a Capacitação. Ficou, assim, demonstrado o objetivo fundamental deste estudo, que esperava ver validado o Questionário MCP-PT na população portuguesa e comprová-lo, também, pela sua conexão positiva com uma ferramenta já testada em Portugal, o PEI/ICC, que, de certo modo, é influenciado pelos moldes em que decorre a consulta. Sabendo que a Capacitação tem correspondência com uma relação mais próxima criada entre o médico e o utente ${ }^{14}$, esperamos estabelecer que a MCP ajuda a que os cuidados de saúde primários permitam uma afinidade crescente entre estes dois intervenientes da consulta.
Gostaríamos de salientar que consideramos que, apesar de representativa, a nossa amostra não é suficientemente grande para inferir que todas as USF se comportam do mesmo modo. Mesmo tendo tentado realizar o estudo em três USF diferentes, realçamos que mais estudos devem ser feitos em Portugal para homogeneizar a amostra.

Acentuamos a importância deste trabalho por não existir até à data um Questionário que avaliasse a MCP na população portuguesa e esperamos que impulsione novos estudos e pesquisas sobre este tema no nosso país.

\section{Conclusão}

O Questionário MCP-PT para a população portuguesa permite aferir a opinião do consulente sobre a aplicação da MCP durante a consulta com o Médico de Família e verificámos uma correlação positiva entre a MCP e a Capacitação, mesmo que $42,5 \%$ da amostra não tivesse em plenitude percebido os seis componentes da MCP.

Deste modo, compreendemos que um método clínico centrado no paciente, que privilegia a comunicação, a parceria e a promoção de saúde, tem repercussões positivas no paciente, que se sente mais habilitado e capaz de lidar com a sua vida e as suas doenças.

\section{Agradecimentos}

Os autores desejam agradecer a todos quantos participaram nos painéis de peritos.

Desejam igualmente agradecer aos consulentes que desinteressadamente deram algum do seu tempo a este processo. 


\section{Referências Bibliográficas}

1. Stewart M et al. (2010) Medicina Centrada na Pessoa: 21-168 $2^{\mathrm{a}}$ Edição, artmed®. Brasil.

2. McWhinney, I; Freeman T. (2010) Medicina de Família e Comunidade: 104-204 3 $3^{a}$ Edição, artmed ${ }^{\circledR}$. Brasil

3. Howie, J.G., D. Heaney, and M. Maxwell, Quality, core values and the general practice consultation: issues of definition, measurement and delivery. Fam Pract, 2004. 21(4): p. 458-68.

4. Ozvacic Adzic, Z., et al., Patient, physician, and practice characteristics related to patient enablement in general practice in Croatia: cross-sectional survey study. Croat Med J, 2008. 49(6): p. 813-23.

5. Little P et al., Observational study of effect of patient centredness and positive approach on outcomes of general practice consultations. Bmj, 2001. 323(7318): p. 908-11.

6. Mercer, S.W., et al., Patient enablement requires physician empathy: a cross-sectional study general practice consultations in areas of high and low socioeconomic deprivation in Scotland. BMC Fam Pract, 2012. 13: p. 6.

7. Lam, C.L., et al., A pilot study on the validity and reliability of the Patient Enablement Instrument (PEI) in a Chinese population. Fam Pract, 2010. 27(4): p. 395-403.

\section{Conflito de Interesses}

Os autores declaram não ter conflitos de interesses.

Financiamento

O trabalho não foi objeto de qualquer tipo de financiamento externo (incluindo bolsas de investigação).

Endereço para Correspondência:

Ana Filipa Reis

Telemovel: 911127252

Email: anafppreis@hotmail.com

Rua do Arco, 8. São Martinho do Bispo

3045-013 Coimbra
8. Stott, N.C. and R.H. Davis, The exceptional potential in each primary care consultation. J R Coll Gen Pract, 1979. 29(201): p. 201-5.

9. Pintalhão, I. et al., Desenvolvimento de Tradução para Português do Patient Enablement Instrument. Revista ADSO, 2013. (02): 18-22

10. Poulton, B.C., Use of the consultation satisfaction questionnaire to examine patients' satisfaction with general practitioners and community nurses: reliability, replicability and discriminant validity. $\mathrm{Br} J$ Gen Pract, 1996. 46(402): p. 26-31.

11. McKinstry, B., I. Colthart, and J. Walker, Can doctors predict patients' satisfaction and enablement? A cross-sectional observational study. Fam Pract, 2006. 23(2): p. 240-5.

12. Ferreira, P.L., Avaliação dos doentes de cuidados primários. Revista Portuguesa de Clínica Geral, 2001. 17: p. 15-45.

13. F., P., Multimorbilidade: Um olhar diferente sobre a doença crónica. Revista ADSO, 2013. 1: p. 11-12.

14. Howie, J.G., et al., Quality at general practice consultations: cross sectional survey. Bmj, 1999. 319(7212): p. 738-43. 


\section{ANEXO 1}

A medicina atual, em particular a que o especialista em Medicina Geral e Familiar pratica, tem a ver com os exercícios de bem compreender, entender e orientar quem vem à sua consulta.

Para podermos melhorar a atuação dos médicos e das equipas de saúde, solicitamos-lhe resposta aos questionários abaixo, o que desde já lhe agradecemos.
Este trabalho está a ser realizado por uma aluna de Medicina na sua Tese de Mestrado.

As suas respostas serão confidenciais (não serão dadas a conhecer a ninguém), anónimas (não serão identificadas) e sigilosas (ninguém saberá quem respondeu) que apenas os resultados serão revelados, em relatório, para que possa haver melhoria da atividade dos médicos.

Preencha por favor os quadros abaixo,

\begin{tabular}{|l|l|l|}
\hline \multicolumn{2}{|l|}{ Idade_anos } & Formação \\
\hline Família & $\square$ Não sabe ler e escrever & Sofre de doença crónica \\
$\square$ Vive só & $\square$ Sabe ler e escrever & $\square$ Sim \\
$\square$ Vive acompanhado & $\square$ Com $9^{\circ}$ ano $\left(4^{\text {a classe })}\right.$ & $\square$ Não \\
\hline Sexo & $\square 12^{\circ}$ ano $\left(7^{\circ}\right.$ ano $)$ & Toma medicamentos regularmente \\
$\square$ Masculino & $\square$ Técnica & $\square$ Sim \\
$\square$ Feminino & $\square$ Superior & $\square$ Não \\
\hline
\end{tabular}

\section{Na consulta de hoje com o seu médico (assinale a resposta com que mais concorda):}

\begin{tabular}{|c|c|c|c|}
\hline Afirmação & \multicolumn{3}{|c|}{ Resposta } \\
\hline Pôde falar sobre o que sentia e sobre os motivos que o levaram à consulta? & $\square$ Não & $\square$ Em parte & $\square \operatorname{Sim}$ \\
\hline $\begin{array}{l}\text { Pôde falar sobre os seus receios e as suas esperanças quanto aos seus } \\
\text { problemas? }\end{array}$ & $\square$ Não & $\square$ Em parte & $\square \operatorname{Sim}$ \\
\hline $\begin{array}{l}\text { Sentiu que o médico se interessa por si, pela sua família e pelas suas } \\
\text { condições de vida? }\end{array}$ & $\square$ Não & $\square$ Em parte & $\square \operatorname{Sim}$ \\
\hline $\begin{array}{l}\text { Sentiu que o processo de tratamento será realizado em conjunto e } \\
\text { colaboração entre si e o seu médico? }\end{array}$ & $\square$ Não & $\square$ Em parte & $\square \operatorname{Sim}$ \\
\hline $\begin{array}{l}\text { Entendeu os objetivos, métodos e possibilidades em relação ao "tratamento" } \\
\text { escolhido? }\end{array}$ & $\square$ Não & $\square$ Em parte & $\square \operatorname{Sim}$ \\
\hline $\begin{array}{l}\text { Percebeu a importância de cumprir as indicações para um "tratamento" } \\
\text { correto e que dê resultados? }\end{array}$ & $\square$ Não & $\square$ Em parte & $\square \operatorname{Sim}$ \\
\hline Percebeu o que deve ser feito para evitar "piorar"? & $\square$ Não & $\square$ Em parte & $\square \operatorname{Sim}$ \\
\hline Aceitou fazer o que Ihe foi proposto para "melhorar"? & $\square$ Não & $\square$ Em parte & $\square \operatorname{Sim}$ \\
\hline $\begin{array}{l}\text { Sentiu que o médico se mostrou interessado em ajudar a resolver o seu } \\
\text { problema? }\end{array}$ & $\square$ Não & $\square$ Em parte & $\square \operatorname{Sim}$ \\
\hline $\begin{array}{l}\text { Compreendeu que o sucesso do tratamento depende de si como doente e de } \\
\text { outros profissionais que trabalham com o seu médico? }\end{array}$ & $\square$ Não & $\square$ Em parte & $\square \operatorname{Sim}$ \\
\hline A consulta com o seu médico durou o tempo necessário? & $\square$ Não & $\square$ Em parte & $\square \operatorname{Sim}$ \\
\hline Esta consulta com o seu médico aconteceu no momento certo? & $\square$ Não & $\square$ Em parte & $\square \operatorname{Sim}$ \\
\hline
\end{tabular}


Como um resultado da sua consulta com o médico hoje, sente que está (assinale a resposta com que mais concorda):

\begin{tabular}{|c|c|c|c|}
\hline & Muito melhor & Melhor & Igual ou pior \\
\hline Capaz de lidar com a vida & $\square$ & $\square$ & $\square$ \\
\hline Capaz de compreender a sua doença & $\square$ & $\square$ & $\square$ \\
\hline Capaz de lidar com a sua doença & $\square$ & $\square$ & $\square$ \\
\hline \multirow[t]{2}{*}{ Capaz de manter-se saudável } & $\square$ & $\square$ & $\square$ \\
\hline & Muito mais & Mais & Igual ou menos \\
\hline Confiante em relação à sua saúde & $\square$ & $\square$ & $\square$ \\
\hline Capaz de se ajudar a si próprio & $\square$ & $\square$ & $\square$ \\
\hline
\end{tabular}

Agradecemos a sua colaboração. 